\title{
The Relationship between Lean Management Accounting Techniques and Decision Making in the Lean Context A Proposed Comprehensive Model
}

\author{
Abeer Mohamed \\ Faculty of commerce, Ain Shams University \\ Email: abeerabdulmoneim@gmail.com
}

\begin{abstract}
:
Purpose- the purpose of this study is to propose a comprehensive model to provide managers with useful information for decision making purpose using the most appropriate Management accounting techniques in the lean context.

Design/methodology/approach- Based on the literature, this study identifies and adapts the most appropriate management accounting techniques to provide managers with useful information for decision making purpose in the lean context and propose a comprehensive model. It also tests the perceptions of managers and management accountants of the Egyptian Pharmaceutical industry concerning the relative merits of such a model.

Findings- The most significant finding in the current study that has not been investigated in previous studies is that the proposed comprehensive model which contains the proposed value stream decision making tool and feature and characteristics (F\&C) technique was a better predictor of decision making of the Egyptian Pharmaceutical industry than the alternative model which contains value stream decision making tool only.

Originality/value- This paper contributes to lean and management accounting literature by proposing a comprehensive model for providing managers with a useful information for decision making using the integration between the most appropriate management Accounting techniques and demonstrating how this integration provides decision makers with useful information. It contributes to strengthening the effectiveness of decision making in the Egyptian Pharmaceutical industry.
\end{abstract}


Keywords: value stream costing, Value stream decision making tool, feature \& characteristics technique, useful information, decision making, Egyptian pharmaceutical industry.

\section{Introduction}

In recent years, many organisations have moved from traditional mass production to lean manufacturing to reduce waste and increase the customer value (Carnes and Hedin, 2005).

To achieve this goal, lean manufacturing is based on the following five principles: define value and identify the value stream; eliminate all non-value added in value stream; make the value flow continuously; base flow on customer pull and pursue perfection continuously (James and Daniel, 1996). The traditional cost accounting techniques are inappropriate for decision-making purposes in the lean context. Therefore, this movement requires adopting new management accounting techniques to provide the decision maker with useful information to make effective decisions in the lean context.

This research focuses on the new management accounting techniques in lean companies and their utilisation to support decision making in manufacturing companies. Providing decision makers with useful financial information is very important, and companies must use the most appropriate management accounting techniques to achieve this. Adopting lean manufacturing has created an opportunity to define a new model for providing decision makers with useful information for decision making purpose, using appropriate management accounting techniques.

The principal aim of this study is to develop a comprehensive model to provide decision makers with useful information in the lean context. This proposed model consists of the proposed value stream decision making tool and F\&C technique. The integration between both techniques can provide decision makers with useful information to effectively make all decisions in the lean context and support the decision-making process. Value stream tool is suggested to provide decision makers with useful information for routine decisions. On the other hand, the F\&C technique is proposed to provide decision makers with useful information for making decisions which require product cost information. 
This research measured the perception of managers and management accountants of these management accounting techniques and their importance in providing decision makers with useful information for decision making purpose in the lean context.

This paper reflects findings from a theoretical model and primary data collection from managers and management accountants in the Egyptian pharmaceutical industry. The model's principles provide a basis for further research and testing of the proposed model in different industries and countries.

\section{Review of Literature on Using Cost Information for Decision Making in the Lean Context}

Traditional management accounting provides decision makers with information related to product costs. This information is used in making routine decisions such as quoting, pricing, sales order profitability, make/buy, sourcing, product or customer rationalisation, and so forth. According to Maskell and Kennedy (2007) and Debusk and Debusk (2012), using product costs are inappropriate and are not incremental for decision making in lean companies because lean manufacturers focus on value streams, not on the products.

The value stream consists of all activities required to serve a customer and create value. It includes all processes that are performed to transform the order received from the customer to a delivered product or service (Baggaley, 2006). Most companies have several value streams, each relating to a different family of products which have similar production elements and process (Maskell, 2000). DeLuzio (2006) illustrates that each value stream will have its profit and loss statement and balance sheet. This allows the value stream manager to make the decisions required to drive profitability and growth within the value stream. This is affirmed by Baggaley and Maskell (2003) who emphasise that the growth and improvement strategies now revolve around the value stream. The principal focus of lean companies is to understand individual value streams and the cost of the value stream as a whole, not the cost of individual products (Gordon, 2010). This is also supported by Maskell and Kennedy (2007) who illustrate that decision making must be focused on evaluating the impact of the decision on the costs and 
profitability of the whole value stream level, not at the product level. Consequently, the value stream's actual cost and profitability are the most appropriate information for decisionmaking in the lean context.

According to Maskell and Kennedy (2007), this information enhances decision making because it is easy to understand and use, readily available each week, accurate and real information instead of the less accurate information and the complex system of calculating product cost.

On the other hand, in some cases, specific product costs are needed for certain decisions in lean companies (Maskell and Kennedy, 2007and Debusk and Debusk, 2014). Traditional management accounting system uses standard costing or activity based costing to calculate product costing and provides management with this information. Such information can be used in decision making. According to Kennedy and Huntzinger (2005) and Baggaley (2006), these traditional methods are inappropriate for lean companies because they were developed for decision-making purposes in mass production companies.

They explain further that these costing methods might be appropriate for mass production, but they are inappropriate for lean production. In mass production, it is impossible to use actual cost in decision making. Mass production is a very complex environment and obtaining the actual cost information is very difficult as it requires a complex and time-consuming study. In lean companies, most decisions need to be made quickly. These traditional costing methods were used as a surrogate for the actual cost in decision making.

Moreover, due to the annual determination of standard costs, the information provided by standard costs is inaccurate as the business environment and the internal process change (Maskell, 2006). Hence, the decisions were made using outdated cost information (Kennedy and Huntzinger, 2005). According to Baggaley and Maskell (2003), the assumptions underlying standard costing fails to support the goals of lean. Also, Debusk and Debusk (2014) argue that activity-based costing information is more costly and includes costs that cannot be controlled at the product level. As such, it is inappropriate for decision making in the lean context.

Many manufacturers implement some level of lean principles throughout the entire organisation. However, traditional management accounting techniques provide decision makers 
with inappropriate cost information for making both routine and non-routine decisions. Thus, traditional management accounting techniques and measurement systems are inappropriate for the decision-making purpose in the lean context.

According to Hilker (2011), the effective cost management system in lean companies should provide relevant and accurate cost information. This information must enable managers to make highly informed data-driven business decisions. Thus, management accounting in a lean enterprise must adopt new techniques and measurement systems. These new techniques provide management with useful data and increase the effectiveness of the decision-making process in the lean context.

Value stream costing is the most appropriate technique suggested by Kennedy and Huntzinger (2005), Maskell and Kennedy (2007), Gordon (2010), and Debusk and Debusk (2012 and 2014) to provide decision makers with information useful for making routine decisions in lean companies. According to Gordon (2010), value stream costing integrates conceptually with lean management concepts based on an understanding of individual value streams. He also emphasises that value stream costing is the most appropriate technique for lean companies because it provides decision makers with useful information by more directly linking accounting and production reports to lean concepts. According to Baggaley and Maskell (2003), the information provided by value stream costing that can be used in decision-making is relevant, accurate, and understandable. This is supported by Maskell (2006) who illustrates that value stream costing provides managers with accurate and timely actual costs information related to value streams. He also points out that the availability of such information can facilitate the decisionmaking process using actual incremental cost analysis. Furthermore, value stream costing has the advantage of simplicity and the ability to properly capture cause and effect relationships between cost and activities (Kennedy and Brewer, 2005; Gordon, 2010).

On the other hand, Debusk and Debusk (2012 I; 2014IV) argue that when specific product costs are needed, lean companies can use F\&C costing instead of maintaining transaction-intensive standard cost systems. This technique calculates product costs and provides managers with an average cost per unit. They affirm that the information provided by this technique is more 
accurate than the other traditional techniques. Also, the cost of using this technique when required is less than the saving from not maintaining the traditional costing system.

Limited studies have suggested the use of both value stream costing F\&C costing techniques in decision making in lean companies (Debusk and Debusk 2012 I; 2014IV). However, previous studies have not developed decision making tool for decision making purpose. Furthermore they have not highlighted the roles of such lean cost techniques in decision making. Moreover, they have not explained how the integration of both techniques could enhance the decision making and increase the effectiveness of the decision-making process. Finally, they have not examined empirically the influence of using both techniques in decision making.

This paper explores the development of a comprehensive model to provide managers with a useful information for the decision making purpose in lean context. This model is adapted from the "value stream costing and "Feature and characteristics cost techniques.

\section{Research methodology:}

Development of such a model is adapted from studies of (Baggaley and Maskell, 2003 II); Kennedy and Huntzinger, 2005; Maskell, 2006 ; Maskell and Kennedy, 2007; Gordon, 2010; Dimi, 2015;Debusk and Debusk , 2012-2014 part IV\&V; Debusk, 2015 and Senge,2007).

Part one of development such a model is to explore appropriate tool to provide managers with useful information for making routine decisions in lean companies.

The financial analysis of routine decisions such as accepting customer orders, make/buy, new products, and rationalization of customers and products should always be made by analyzing the impact of the decision on the profitability of the value stream as a whole using value stream costs and profitability report (Senge,2007).

Regarding to determine and make the pricing decision, the main driver for determining price is the customer value which is not related to product cost. Moreover, if the prices are market driven, it is not helpful to determine profitability by referencing the product cost. The right approach is to focus on the potential order and its effect on the value stream profitability, taking into 
account of any additional costs that will be associated with this order. Make/buy decision is also made with reference to the profitability of the value stream and never made with reference to product cost. The only information required for this decision is the capability and the capacity that the value stream has to produce specific part. If the value stream has the capability and capacity to make a part, then no additional cost for making this part because the cost machine, people, and the facility is already being paid for. Thus, in this case, there is no financial reason to buy this part.

Therefore the most appropriate tool to make routine decisions in lean companies is the "value stream cost and profitability report". This report is prepared using value stream costing technique which focuses on the cost and profitability of the entire value stream. Such a report uses as a primary tool in providing decision makers with useful financial information which enhances the effectiveness of decision making process (Van and Thomson, 2007).Cost and profitability report is prepared on the weekly or monthly base. This report includes the actual value stream revenue and the actual value stream costs.

Value stream revenue is the sum of the actual total amount of invoices processed for products produced in the value stream. Value stream costing includes all costs within the value stream. These costs are considered direct cost. Other costs outside the value stream do not included in the value stream costing. The total value stream costs consists of labor costs; material costs; support costs; and facilities costs. Labor costs are the sum of the wages and other benefits paid to people working in the value stream whether they produce the product, move materials, design the product, maintain machines, or do the accounting. This information is collected from the payroll system. If the inventory is low and under effective control, the material costs of value stream will be the cost of materials purchased for the value stream over the week. Support costs such as supplies, tooling and other day to day expenses are applied simply to the value stream or collected from the account payable process. Facilities costs include rent or lease cost of building, utilities, and maintenance cost for building. The only allocation adopted in the value stream costing technique is a square footage. The purpose of this allocation is to encourage the value stream team members to 
reduce the amount of space used by the value stream. This allocation starts with the calculation of cost per square foot. This is calculated by divided total costs by total square footage of the building. The facilities cost assigned to the value stream are finally calculated by multiply the cost per foot by the amount of square feet used by value stream such as ( production area, stockroom area, and the office apace area used by people working in the value stream). The costs that do work crosses all value streams (non-value stream tasks), are not allocated to the value streams. They are considered as sustaining costs of the business.

Other significant factor can be used in decision making is suggested by (Dimi, 2015). The author suggested the use of capacity indicators in decision making. The capacity information shows how much of the stream's resources are used productivity, how much is used nonproductively, and how available capacity is within the value stream (the time remains after doing productive and nonproductive work) (Senge, 2007). Lean thinking principle aims to reduce the activities that do not create value which lead to create the available capacities. The capacity has to be present in terms of employees and in terms of machinery. This capacity information is calculated through job card or labor summary as work done by the people and machines in the available time or resources

The current study proposed tool that can be used to increase and measure the effectiveness of decision making by focusing the identification the available capacity indicators and measuring the financial impact of the business decisions on the value stream. This tool is adapted from the studies of (Dimi, 2015); (Haskin, (2010); (Maskell and Kennedy,2007); (Maskell , Kennedy and Grasso,2007) and (Senge, 2007). 
The following table presents the proposed tool for decision making in lean context:

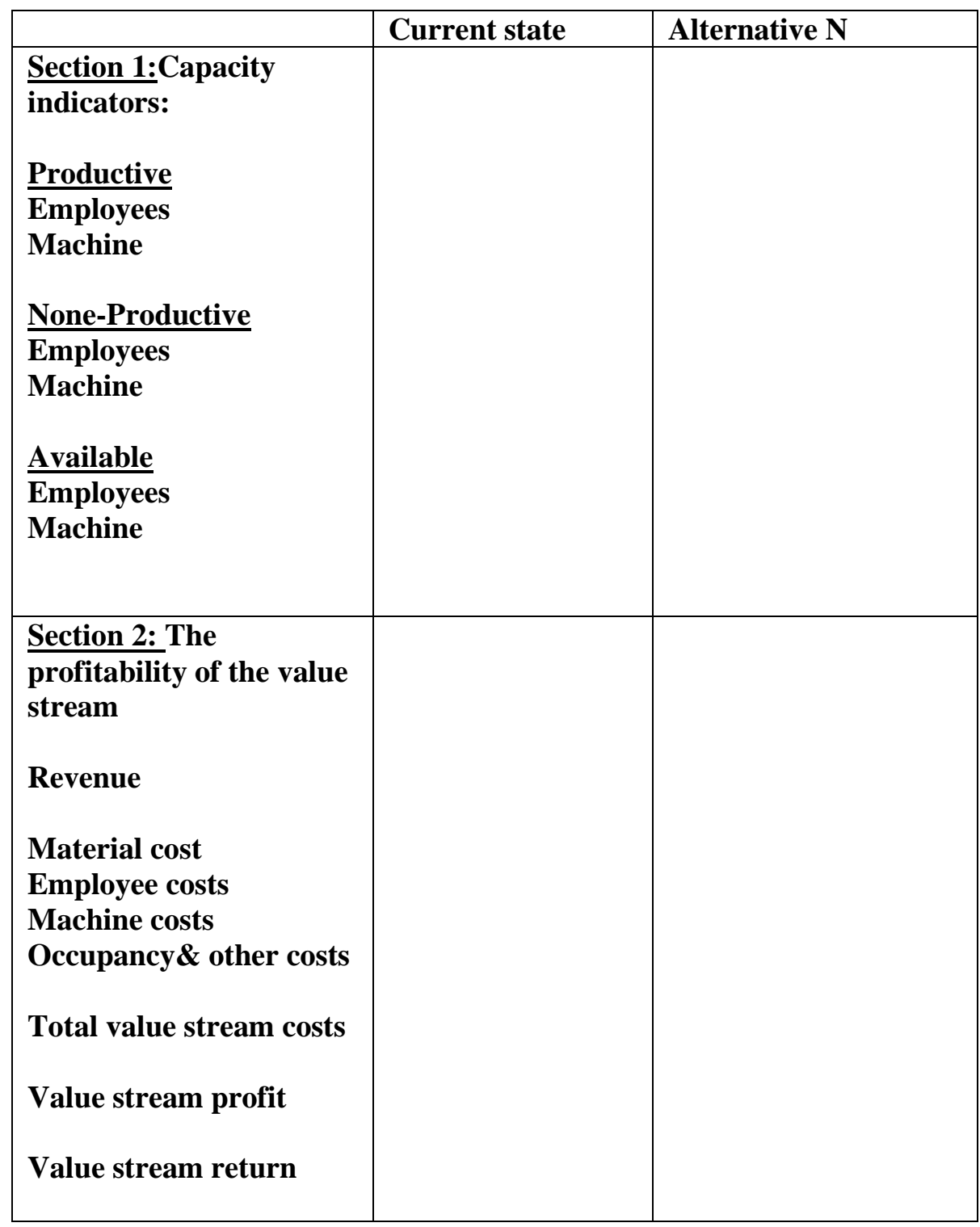

This proposed decision making tool has the advantage to accurately reflect the real activity, in financial terms, within a company in different given situations, and increase the quality of decisions because the information presented eliminates some of the waste elements which are specific to traditional accounting systems. It provides a correct way of making appropriate decisions. It also ensures a proactive basis in providing the 
information for managerial decisions (Dimi, 2015).It also provides understandable, timely and simple information which enhance the decision making process in the lean context.

Part two of this model is focusing in propose appropriate technique for other special decision.

The proposed technique adopted by the current study for the special decision making purpose is Feature and characteristics cost. It is a new technique uses to calculate product costs for lean companies. It is adopted as ad hoc analysis when required for some special decisions in lean context. The total product cost calculated by feature and characteristics cost is the sum of material cost and conversion cost. This technique is based on the principal that conversion costs within value stream are highly correlated with time spent in the bottleneck point. Feature and characteristics cost technique investigates the effects of feature and characteristics of product on the flow rate through the bottleneck. This information is used to calculate the conversion cost for product. The first step to apply this cost technique is to identify the product features and characteristics and their impact on process time. The second step is to determine the constraint process which is the most time consuming process. The most important step is to calculate the product flow rate per hour and then per day for each product feature and characteristic (60 minutes/processing time in the constraint and then multiply the results with 8 hours to get the daily rate). Finally, determine the average conversion cost per unit (conversion cost per day divided by the flow rate per day each product feature and characteristic).

The use of F\&C costing can be very useful tool to the company in obtaining estimated product costs where there are multiple products manufactured in a value stream consuming resources at different rates. Using this technique is also provides the managers with the accurate and relevant information to select which products to produce and determine the product mix. Moreover,this technique is also useful in preparing the required analyses for quality Function development. In QFD, companies focus on customer to determine the value of product features. This customer value can be related to what the customer is willing to pay for this feature. F\&C costing provide company with the average costs to those features. This information can be used in calculating profitability by product features. This information could be very useful in some strategic decisions such as pricing of 
products and determine which products to sell. In addition, studying the differences between customer value and average cost of the product features, provide managers with relevant information for decision making such as cost reduction decisions to close the gap between cost and customer value. Furthermore, lean organization can turn to $F \& C$ costing to provide the estimated average cost per unit when required for long-term strategic analyses.

It can be concluded that the integration between the proposed value stream decision making tool and feature\& characteristics costing technique provides decision makers with the following:

1. All required details for both routine decisions and other special decisions.

2. Incremental information represented in the profitability value stream and capacity indicators for routine decision making and average product cost using feature\& characteristics for other special decision.

3. Sufficient accurate information for all decisions because value stream provide decision maker with the actual information which means that it is accurate and feature\& characteristics costing provide decision maker with the average product cost based on the relationship between product features and customer value which is also accurate information in lean context.

4. Weekly value stream costing information and feature costing information when required (on the time). This availability facilitates decision making process; and Easy information to use and to understand by non-accountants, because it is presented in a simple format with obvious details.

It can be concluded from the creation of the model section and from the above discussion that the proposed model provides managers with a useful information for decision making purpose in lean context by providing managers with relevance, reliability, completeness, timeliness, understandability, verifiability and accessibility information, which are the characteristics of useful information for decision making (Romney; Steinbert and Cushing, 2006). 
The following figure illustrates the proposed model and its variables:

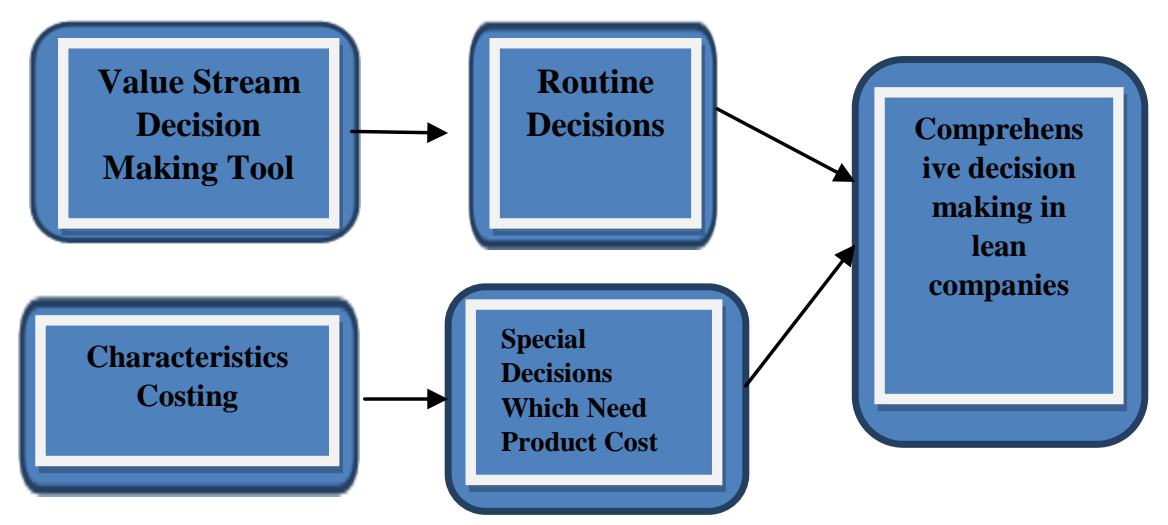

Figure 1 - A proposed comprehensive model for using Management Accounting information in decision making in lean context

In this proposed model dependent variables and their measures for proposed model can be presented in the following table:

\begin{tabular}{|l|l|}
\hline $\begin{array}{l}\text { Dependent variables for } \\
\text { proposed model }\end{array}$ & $\begin{array}{l}\text { Measures (the characteristics of } \\
\text { useful information for decision } \\
\text { making). }\end{array}$ \\
\hline $\begin{array}{l}\text { Routine decision } \\
\text { Other special decision the } \\
\text { decision making in lean } \\
\text { context. }\end{array}$ & $\begin{array}{l}\text { Relevance, } \\
\text { Reliability, } \\
\text { And the comprehensive } \\
\text { decision making in lean } \\
\text { context }\end{array}$ \\
\hline
\end{tabular}

The independents variables are:

The proposed decision making tool;

Feature and characteristics costing technique F\&C.

The proposed model hypotheses are tested through evaluating the perceptions of managers about the impact of such a model on decision making in lean context. Thus, hypotheses for the proposed model can be formulated as follows:

H1: The use of proposed value stream decision making tool is related to the routine decisions making lean context. 
H2: The use of feature/characteristics costing technique is related to the special decisions that required specific product costs in lean context.

H3: The integration between the proposed value stream decision making tool and feature/characteristics costing technique is greatly related to the decision making in lean context.

\section{Approach to test the model}

\section{Population and Sample}

The pharmaceutical industry has a strategic importance for the development of a healthy and productive nation. Today, the pharmaceutical industry is considered e one of the largest and rapidly growing global industries. It is a major source of employment generation and foreign exchange earnings for many countries. Therefore, the target population in the current study is the Egyptian pharmaceutical industry.

Due to time and resource restrictions, a judgement sample is used in the current study. The study focuses only on the pharmaceutical manufacturers who are members pharmaceutical Chamber. The determination of such a sample is justified as follows. Firstly, all the members are registered in the Federation of Egyptian Industries and have annual financial reports, in addition to which they have financial departments and hence have specialists in the accounting field who are more likely to be interested in the current study. Secondly, members of the pharmaceutical chamber have a database containing detailed information about company profile, profit and loss accounts, ratios and trends, and all site and trading addresses and contact details. All of this information makes it easy to contact possible respondent companies, which represents a difficult task in Egypt as a developing country.

The sample is drawn from the Federation of Egyptian Industries' database. Within the Egyptian pharmaceutical sector (population) the sample included all those members of CPH. The sample frame was 154 manufactures (the total membership of $\mathrm{CPH}$ at the time) (FEI, 2015). The respondents were management accountants, production managers, sales managers, and factory managers because they are able to comment 
accurately on the aspects in the questionnaire since they have expertise in decision-making at the strategic level.

\section{Questionnaire Development}

A questionnaire was used to collect the data. A selfadministrated questionnaire, delivered and collected by hand, was utilised to test the proposed framework. This framework was used to develop the questionnaire to test the proposed framework. The objective of this questionnaire was to collect data about the perception of managers and management accounts related to each variable in the framework and their relationships, which can then be used in evaluating the developed decision-making framework. To achieve this objective, the questionnaire was divided into three main sections (the proposed value stream decision making tool and routine decisions, F\&C costing and related special decisions, the impact of the integration between value stream decision making tool and $\mathrm{F} \& \mathrm{C}$ on the effectiveness of decision making).

Care was taken to ensure that questions covered all theoretical constructs contained in the proposed framework. In addition, a 5-point Likert-type scale (from (1) not important to (5) very important for some questions and from (1) completely disagree to (5) completely agree with others) was used in most questions.

In this research, closed question format was deemed the most appropriate type due to the pressure of respondents' time and a cultural dislike of such open questions, as they require a detailed answer, closed questions were deemed to be most appropriate.

The questionnaire was pre-tested and evaluated by six reviewers, two academics familiar with the Egyptian pharmaceutical industry, one academic statistician specialising in accounting research and three practitioners. Reviewers were asked to test the questionnaire and identify unclear items and suggest changes. Changes were made, based on the comments and suggestions received from the reviewers.

\section{Response Rate Strategies}

Questionnaires were distributed by hand to 600 individuals (154 manufactories). After one week, companies which had not replied within the first week were contacted by phone as a reminder. After three weeks a reminder letter with another copy of the questionnaire was delivered by hand to companies which had not 
replied. 430 individuals apologised for not completing the questionnaire. Of the completed questionnaires, 100 were completed and collected after the first delivery. 20 were collected after the first follow-up process. A further 50 were collected after the second follow-up process. A total of 170 completed questionnaires were received.

\section{Response Bias}

Once all questionnaires were returned a test was conducted to ensure that there was no significant difference between the responses received in the early and late stages of data collection. To enact this, the first and last 50 questionnaires were compared. The figure of 50 was used based on the slightly smaller number of a questionnaire received in the second phase and to ensure an equal sample size for comparison. The testing was done through the application of the two sample Kolmogorov-Smirnov test. The test showed that of the $\mathbf{1 0 0}$ variables there was no significant difference.

\section{Findings Discussion and Implication}

Factor analysis for the variables of the proposed techniques

Structural factor analysis was applied for variables of the proposed value stream decision making tool which based on the value stream costing approach and the characteristics and feature cost technique to examine the underlying relationships between variables. Common factor analysis with principal component was used.

For the proposed value stream tool. Nine items from 20 included in the analysis have communality values ranging from 0.4 to 0.7 (from lower to moderate), which are common magnitudes in social science (Velicer and Fava, 1998). Eleven items have communality values above 0.7 , which represent high communality.

In addition, most of the items have a factor loading above 0.49. Furthermore, all items are loaded highly on only one factor and are not split-loaded. Principal component provided a two-factor solution with eigenvalues of 1.0 or above, and 20 items are retained under the two factors which explain 62 per cent of the variance in the data set. The first factor explains 23 per cent of the variance, the second for 39 per cent. None of the remaining 
factors are significant. For reliability analysis, Cronbach's alpha is calculated to test reliability and internal consistency for each factor. The result indicates that the alpha coefficient for all factors is above 86 per cent, which is higher than the standard estimates of 0.70 (Howitt and Cramer, 2008). In addition, the Spearman's inter correlation for the two factors is significant at the 0.001 level. The factors are labelled according to the commonality of items loading on each factor and they are labelled as follows: Capacity indicators and The profitability of the value stream For characteristics and feature cost technique variable. Among the 12 items included in the analysis, 4 have communality values ranging from 0.4 to 0.7 (from lower to moderate), which are common magnitudes in social science (Velicer and Fava, 1998). On the other hand, two items have communality values less than 0.4 , which means that they do not fit well with a factor solution and should be dropped from the analysis (Velicer and Fava, 1998). In addition, most of the items have a factor loading greater than 0.69 , indicating a strong correlation between items and the factor they belong to. Furthermore, all items are loaded highly on only one factor and are not split-loaded on another factor above 0.32 (Tabachnick and Fidell, 2001).

Principal component provides a four-factor solution with eigenvalues of 1.0 or above being extracted, and the 10 items which are retained under the four factors explain 61 per cent of the variance in the data set. The first factor accounts for 20 per cent of the variance, the second for 18 per cent, the third for 18 per cent and the fourth for 5 per cent. None of the remaining factors is significant. For reliability analysis, Cronbach's alpha is calculated to test reliability and internal consistency for each factor. The result indicates that the alpha coefficient for all factors is above 86 per cent, which is higher than the standard estimates of 0.70 (Howitt and Cramer, 2008). In addition, the Spearman intercorrelation for the four factors is significant at the 0.001 level. The factors are labelled according to the commonality of items loading on each factor and are as follows:

Identify the product features and characteristics, determine the constraint process, calculate the product flow rate and determine the average conversion cost per unit. 


\section{Testing Hypotheses}

The relationship between the proposed value stream decision making tool and routine decisions

Stepwise linear regression analysis is utilised to test the relationship between the use of the proposed value stream decision making tool and the routine decision. In addition, it also used to evaluate whether both value stream profitability and capacity indicators are necessary to predict routine decision making. Finally, it is performed to determine the relative importance of each independent variable in the model (Anonymous I, 2016).

Variables Entered/Removed ${ }^{\mathrm{a}}$

\begin{tabular}{|l|l|l|l|}
\hline Model & $\begin{array}{l}\text { Variables } \\
\text { Entered }\end{array}$ & $\begin{array}{l}\text { Variables } \\
\text { Removed }\end{array}$ & \multicolumn{1}{|c|}{ Method } \\
\hline 1 & VSP* & $\cdot$ & $\begin{array}{l}\text { Stepwise (Criteria: Probability-of-F-to- } \\
\text { enter }<=.050, \text { Probability-of-F-to-remove } \\
>=.100) .\end{array}$ \\
2 & CIs** & $\cdot \begin{array}{l}\text { Stepwise (Criteria: Probability-of-F-to- } \\
\text { enter <=.050, Probability-of-F-to-remove } \\
>=.100) .\end{array}$ \\
\hline
\end{tabular}


Variables Entered/Removed ${ }^{\mathrm{a}}$

\begin{tabular}{|l|l|l|l|}
\hline Model & $\begin{array}{l}\text { Variables } \\
\text { Entered }\end{array}$ & $\begin{array}{c}\text { Variables } \\
\text { Removed }\end{array}$ & \multicolumn{1}{|c|}{ Method } \\
\hline 1 & VSP* & $\begin{array}{l}\text { Stepwise (Criteria: Probability-of-F-to- } \\
\text { enter <=.050, Probability-of-F-to-remove } \\
>=.100) .\end{array}$ \\
2 & $\cdot$ & $\begin{array}{l}\text { Stepwise (Criteria: Probability-of-F-to- } \\
\text { enter < = .050, Probability-of-F-to-remove } \\
>=.100) .\end{array}$ \\
\hline
\end{tabular}

* Value stream profitability

** Capacity indicators

a. Dependent Variable: RD

Table I shows which independent variables are included in the model at each step. Value stream profitability is the best predictor (step 1), and capacity indicators is the next best predictor (added the most), after value stream profitability was included in the mode (step 2).

\begin{tabular}{|l|c|c|c|c|c|}
\hline \multirow{2}{*}{ Model } & R & R Square & $\begin{array}{c}\text { Adjusted R } \\
\text { Square }\end{array}$ & $\begin{array}{c}\text { Std. Error of } \\
\text { the Estimate }\end{array}$ & $\begin{array}{c}\text { Durbin- } \\
\text { Watson }\end{array}$ \\
\hline 1 & $.784^{\mathrm{a}}$ & .614 & .612 & .296 & \\
2 & $.827^{\mathrm{b}}$ & .685 & .681 & .268 & 1.677 \\
\hline
\end{tabular}

In the regression summary shown in Table II, a coefficient of $0.827(\mathrm{R})$ suggests there is a strong positive relationship between the routine decision making and the integration between VSP and CIs (model 2). Moreover, adjusted R Square with 'value stream profitability' alone, $61 \%$ of the variance was accounted for. With both "value stream profitability" and 
"capacity indicators (model 2), around $68 \%$ of the variance was accounted for.

This means that the integration explains 68\% (Adjusted $R$ Square) of variability in the routine decision making between the VSP and CIs which is better predicted with the changes of routine decision making than the other model which includes VSP only.

In addition, the result of testing the auto-correlation assumption is also shown that Durbin-Watson (d) is $\mathbf{1 . 6 7 7}$ (the two critical values of $1.5<d>2.5$ ). Therefore, it can be assumed that there is no linear autocorrelation.

\begin{tabular}{|c|c|c|c|c|c|c|}
\hline \multicolumn{7}{|c|}{$\mathrm{ANOVA}^{\mathrm{c}}$} \\
\hline & Model & $\begin{array}{l}\text { Sum of } \\
\text { Squares }\end{array}$ & df & $\begin{array}{c}\text { Mean } \\
\text { Square }\end{array}$ & $\mathbf{F}$ & Sig. \\
\hline \multirow[t]{3}{*}{1} & Regression & 25.998 & 1 & 25.998 & 297.495 & $.000^{a}$ \\
\hline & Residual & 16.342 & 187 & .087 & & \\
\hline & Total & 42.340 & 188 & & & \\
\hline \multirow[t]{3}{*}{2} & Regression & 28.984 & 2 & 14.492 & 201.816 & $.000^{b}$ \\
\hline & Residual & 13.356 & 186 & .072 & & \\
\hline & Total & 42.340 & 188 & & & \\
\hline
\end{tabular}

ANOVA table shows two F-tests, one for each step (model) of the procedure. Both steps had overall significant results $(p=.000$ for VSP alone, and $p=.000$ for VSP and CIs). For instance, the second model, $F=201.816$ which means that the value is very high and that VSP and CIs are different. Moreover, the significance $=0$ which means that the confident level is $\mathbf{1 0 0 \%}$. Therefore, the high value of $F$ and significant level at $p<.005$ indicate that the VSP and CIs are different from each other and they affect the routine decision making in different manner. It can be concluded that there is a linear relationship between variables in the regression models and the models do improve the prediction. 
Coefficients $^{\mathrm{a}}$

\begin{tabular}{|c|c|c|c|c|c|c|c|c|}
\hline \multirow{2}{*}{\multicolumn{2}{|c|}{ Model }} & \multicolumn{2}{|c|}{$\begin{array}{c}\text { Unstandardized } \\
\text { Coefficients }\end{array}$} & \multirow{2}{*}{$\begin{array}{c}\text { Standardized } \\
\text { Coefficients } \\
\text { Beta } \\
\end{array}$} & \multirow[b]{2}{*}{ t } & \multirow[b]{2}{*}{ Sig. } & \multicolumn{2}{|c|}{$\begin{array}{c}\text { Collinearity } \\
\text { Statistics } \\
\end{array}$} \\
\hline & & B & Std. Error & & & & Tolerance & VIF \\
\hline \multirow[t]{2}{*}{1} & (Constant) & 1.052 & 1.95 & & 8.544 & .000 & & \\
\hline & VSP & .634 & .049 & .684 & 12.248 & .000 & 1.000 & 1.000 \\
\hline \multirow[t]{3}{*}{2} & (Constant) & 1.669 & .195 & & 8.544 & .000 & & \\
\hline & VSP & .743 & .066 & .583 & 11.297 & .000 & .637 & 1.570 \\
\hline & CIs & .308 & .048 & .333 & 6.448 & .000 & .637 & 1.570 \\
\hline
\end{tabular}

a. Dependent Variable: RD

Table IV shows the regression coefficients, the intercept and the significance of all coefficients and the intercept in the model. Coefficients change depending on which predictors are included in the model. Such coefficients are the weights of independent variables which reflect the relative importance of each independent variable.

It can be seen that the best regression model is the second model which includes both VSP and CIs because the weights of coefficients are higher than the first one. For the regression equation that includes VSP and CIs (the two best predictors In addition, the result of multicollinearity assumption test is also shown in the above table. The tolerance value is $>0.1$ which means that no multicollinearity in the data and VIF $<10$ which also confirms that no multicollinearity in the data.

Therefore, the hypothesis (H1) that the use of the proposed value stream tool and capacity indicators are related to the routine decision making in the lean context can be accepted. This means that this integration is required to support routine decision making and provide managers with useful information for decision making purpose in the lean context. This finding has not been empirically investigated in previous studies. However it is supported by the works of Kennedy and Huntzinger (2005); Maskell (2006) ; Maskell and Kennedy (2007);Gordon (2010); Debusk and Debusk (2012-2014 part IV \&V); Dimi, (2015); Haskin, (2010); Maskell and Kennedy,(2007); Maskell, Kennedy and Grasso,(2007) and Senge, (2007), in that VSC technique is 
the most appropriate technique that can be used for the routine decisions making purpose in lean context.

The relationship between the use of feature \& characteristics costing technique and the other special decisions.

A Pearson's correlation is adopted to test the association between $F \& C$ costing and the other special decisions. The result of this test indicates that a statistically significant correlation at .005 level exists between F\&C costing and the other special decisions, with a high positive correlation coefficient of $\mathbf{. 7 4 9}$ (p<.005) (Hair et al., 2007). Such a result suggests that using F\&C costing positively affects the other special decisions.

Therefore, the hypothesis (H2) that the use of the F\&C technique is related to other special decisions making in the lean context can be accepted. This means that the information provided by the $F \& C$ technique is strongly affected the special decisions which require product costs information in the lean context. This also emphasises that the $F \& C$ technique provides decision makers with the required and useful information for such decisions. This finding has not been investigated empirically in previous studies. It is supported by Debusk and Debusk (2012-2014 part IV \&V) in that the F\&C technique is the most appropriate technique can be used for the special other decisions which require product cost information in the lean context.

Relationship between the use of the proposed value stream decision making tool and Feature \& characteristics costing technique, and comprehensive decision making

Stepwise linear regression analysis is utilised to test the relationship between the use of proposed value stream decision making tool and F\&C costing techniques, and the comprehensive decision-making. In addition, it also used to evaluate whether both value stream proposed tool and F\&C techniques are necessary to predict decision making. Finally, it is performed to determine the relative importance of each independent variable in the model (Anonymous I, 2016). SPSS is used to carry out the regression model. In building stepwise linear regression model, regression assumptions are also 
examined. Such assumptions must be met for linear regression to be performed. The following are the results and interpretations of stepwise linear regression model and its assumptions (Anonymous 2, 2016):

Table I

\begin{tabular}{|c|c|c|c|}
\hline Model & $\begin{array}{l}\text { Variables } \\
\text { Entered }\end{array}$ & $\begin{array}{l}\text { Variables } \\
\text { Removed }\end{array}$ & Method \\
\hline 1 & VST & . & $\begin{array}{l}\text { Stepwise } \\
\text { (Criteria: } \\
\text { Probability- } \\
\text { of-F-to-enter } \\
<=.050, \\
\text { Probability- } \\
\text { of-F-to- } \\
\text { remove >= } \\
.100) \text {. }\end{array}$ \\
\hline 2 & FC & . & $\begin{array}{l}\text { Stepwise } \\
\text { (Criteria: } \\
\text { Probability- } \\
\text { of-F-to-enter } \\
<=.050, \\
\text { Probability- } \\
\text { of-F-to- } \\
\text { remove >= } \\
\text {.100). }\end{array}$ \\
\hline
\end{tabular}

a. Dependent Variable: DM

Table I shows which independent variables are included in the model at each step. Value stream proposed tool is the best predictor (step 1), and F\&C costing is the next best predictor (added the most), after value stream costing was included in the mode (step 2).

Table II

Model Summary ${ }^{\mathrm{c}}$

\begin{tabular}{|l|l|l|l|l|l|}
\hline Model & R & R Square & $\begin{array}{l}\text { Adjusted R } \\
\text { Square }\end{array}$ & $\begin{array}{l}\text { Std. Error of } \\
\text { the Estimate }\end{array}$ & $\begin{array}{l}\text { Durbin- } \\
\text { Watson }\end{array}$ \\
\hline 1 & $.738^{\text {a }}$ & .507 & .577 & .366 & \\
2 & $.777^{\mathbf{b}}$ & .558 & .598 & .354 & 1.766 \\
\hline
\end{tabular}

In the regression summary shown in Table II, a coefficient of $0.777(R)$ suggests there is a strong positive relationship between the effectiveness of decision making and the integration between VST and F\&C technique (model 2). Moreover, adjusted $R$ 
Square with 'value stream proposed tool' alone, $57.7 \%$ of the variance was accounted for. With both "value stream tool" and "F\&C costing" (model 2), around $59.8 \%$ of the variance was accounted for.

This means that the integration explains 59.8\% (Adjusted $R$ Square) of variability in the effectiveness of decision making between the VSP and F\&C technique which is slightly better predicted with the changes of decision making than the other model which includes VST only.

In addition, the result of testing the auto-correlation assumption is also shown that Durbin-Watson (d) is $\mathbf{1 . 7 6 6}$ (the two critical values of $1.5<d>2.5$ ). Therefore, it can be assumed that there is no linear autocorrelation.

Table III

ANOVA $^{\mathrm{c}}$

\begin{tabular}{|ll|l|l|l|l|l|}
\hline \multicolumn{2}{|c|}{ Model } & $\begin{array}{l}\text { Sum of } \\
\text { Squares }\end{array}$ & Df & $\begin{array}{l}\text { Mean } \\
\text { Square }\end{array}$ & F & Sig. \\
\hline 1 & Regression & 26.202 & 1 & 24.201 & 201.893 & $.000^{\text {a }}$ \\
& Residual & 22.982 & 185 & .122 & & \\
& Total & 49.185 & 186 & & & \\
\hline 2 & Regression & 25.720 & 2 & 12.860 & 106.434 & $\mathbf{. 0 0 0}^{\text {b }}$ \\
& Residual & 22.474 & 186 & .121 & & \\
& Total & 48.195 & 188 & & & \\
\hline
\end{tabular}

ANOVA table shows two F-tests, one for each step (model) of the procedure. Both steps had overall significant results $(p=.000$ for VST alone, and $p=.000$ for VST and F\&C). For instance, the second model, $F=106.434$ which means that the value is very high and that VST and F\&C techniques are different. Moreover, the significance $=0$ which means that the confident level is $100 \%$. Therefore, the high value of $F$ and significant level at $p<.005$ indicate that the VST and F\&C technique are different from each other and they affect the effectiveness of decision making in different manner. It can be concluded that there is a linear relationship between variables in the regression models and the models do improve the prediction. 
Table IV

Coefficients $^{\mathrm{a}}$

\begin{tabular}{|c|c|c|c|c|c|c|c|}
\hline \multirow[b]{2}{*}{ Model } & \multicolumn{2}{|c|}{$\begin{array}{l}\text { Unstandardized } \\
\text { Coefficients }\end{array}$} & \multirow{2}{*}{$\begin{array}{l}\text { Standardized } \\
\text { Coefficients } \\
\text { Beta }\end{array}$} & \multirow[b]{2}{*}{$\mathbf{t}$} & \multirow[b]{2}{*}{ Sig. } & \multicolumn{2}{|c|}{ Collinearity Statistics } \\
\hline & B & Std. Error & & & & Tolerance & VIF \\
\hline $\begin{array}{ll}1 & \text { (Constant) } \\
& \text { VST }\end{array}$ & $\begin{array}{l}.489 \\
.591\end{array}$ & $\begin{array}{l}.229 \\
.058\end{array}$ & .599 & $\begin{array}{l}5.961 \\
10.217\end{array}$ & $\begin{array}{l}.000 \\
.000\end{array}$ & 1.000 & 1.000 \\
\hline $\begin{array}{ll}2 & \text { (Constant) } \\
& \text { VST } \\
& \text { FC } \\
\end{array}$ & $\begin{array}{l}.687 \\
.852 \\
.139\end{array}$ & $\begin{array}{l}.245 \\
.065 \\
.062\end{array}$ & $\begin{array}{l}.799 \\
.123\end{array}$ & $\begin{array}{l}2.786 \\
13.294 \\
2.072 \\
\end{array}$ & $\begin{array}{l}.006 \\
.000 \\
.040\end{array}$ & $\begin{array}{l}.711 \\
.711\end{array}$ & $\begin{array}{l}1.406 \\
1.406\end{array}$ \\
\hline
\end{tabular}

Table IV shows the regression coefficients, the intercept and the significance of all coefficients and the intercept in the model. Coefficients change depending on which predictors are included in the model. Such coefficients are the weights of independent variables which reflect the relative importance of each independent variable.

It can be seen that the best regression model is the second model which includes both VST and FC technique because the weights of coefficients are higher than the first one. For the regression equation that includes VST and F\&C (the two best predictors), the equation would be: Decision making $=.687+.852$ VST +.139 F\&C. This means that each time VST and F\&C increase by 1000, the effectiveness of decision-making increase by 852 and 139 anticipating that the VST and F\&C are held constant. Therefore, both the VST and F\&C are important to enhance decision making. However, the relative importance of the VST is higher than the relative importance of $F \& C$.

In addition, the result of multicollinearity assumption test is also shown in the above table. The tolerance value is $>0.1$ which means that no multicollinearity in the data and VIF $<10$ which also confirms that no multicollinearity in the data.

Table V

Tests of Normality

\begin{tabular}{|l|l|l|l|l|l|l|}
\hline \multirow{2}{*}{} & \multicolumn{3}{|l|}{ Kolmogorov-Smirnov $^{\mathrm{a}}$} & \multicolumn{3}{l|}{ Shapiro-Wilk } \\
\cline { 2 - 7 } & Statistic & Df & Sig. & Statistic & Df & Sig. \\
\hline DM & .137 & $\mathbf{1 8 9}$ & .200 & .946 & $\mathbf{1 8 9}$ & .316 \\
\hline
\end{tabular}

Lilliefors Significance Correction 
The test of normality assumption is shown in Table V. Here two tests for normality are run. For dataset small than 2000 elements, the Shapiro-Wilk test is used. Otherwise, the Kolmogorov-Smirnov test is used. In this case, since we have only 189 elements, the Shapiro-Wilk test is used. From A, the pvalue is 0.316. Therefore, the alternative hypothesis can be rejected concluding that the data comes from a normal distribution.

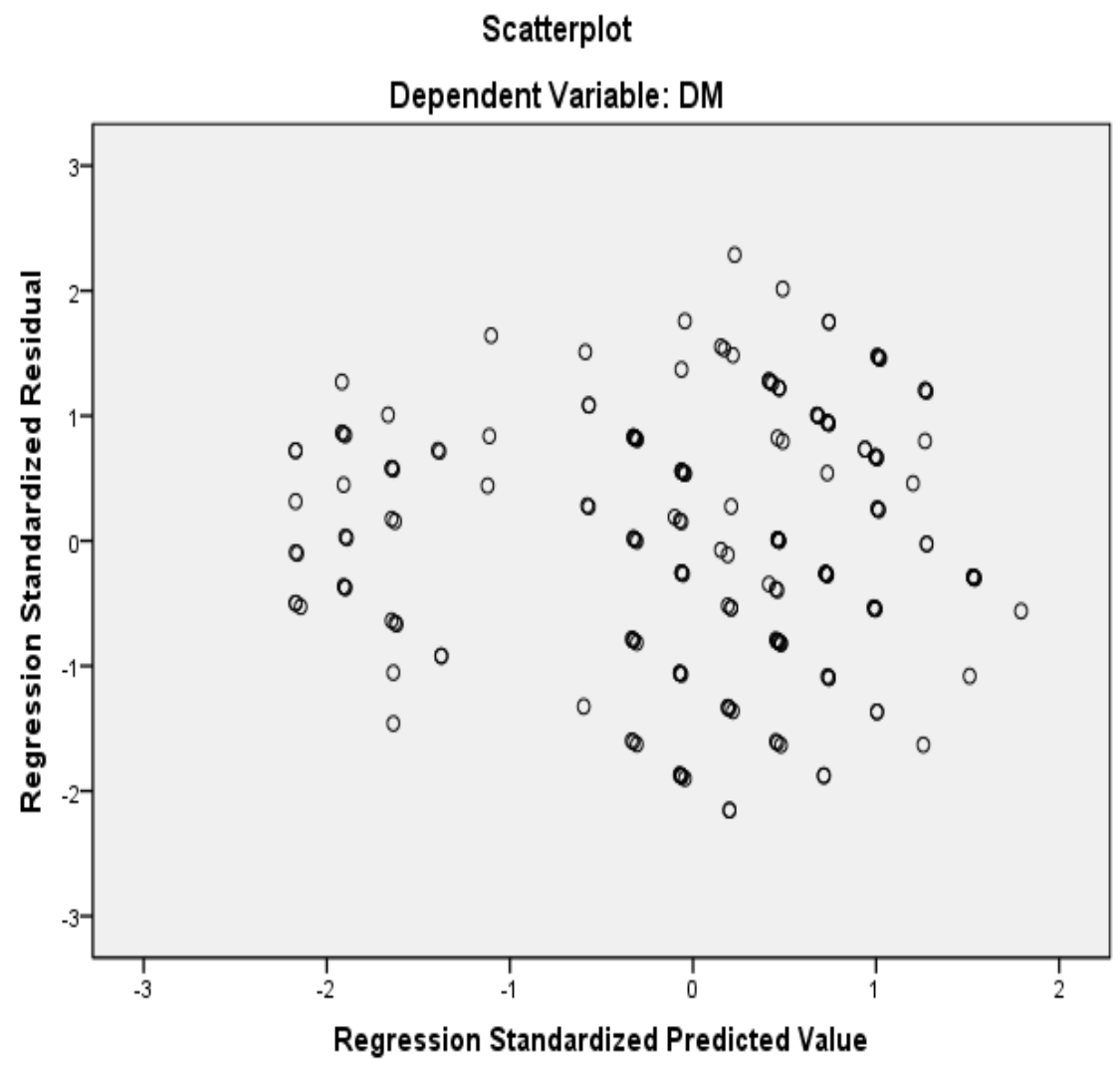

The homoscedasticity assumption is tested using the scatterplot (Figure 2). It shows how large standardised residual was in each value of the predicted outcome. The data points seem fairly randomly distributed with a fairly even spread of residual at all predicted value. This confirms the fulfilment of the homoscedasticity assumption.

The most significant findings in the current study showed in the stepwise regression tables. The most important finding that has not been examined in previous studies is that the proposed 
comprehensive model which includes value stream proposed tool and $F \& C$ costing techniques predicted a higher level of decision making. This result emphasises that the integration between both techniques better enhance decision making than the other model which include the VST only.

Therefore, the hypothesis (H3) that the use of value stream decision making tool and $\mathrm{F} \& \mathrm{C}$ costing techniques is related to the decision making in the lean context can be accepted. This means that both techniques are required to provide managers with useful information for decision making purpose in the lean context.

A significant finding of this study which has not been investigated in previous studies suggests that the integration between the value stream tool that consists of the value stream profitability and capacity indicators and feature and characteristics costing is the best model that can be used to enhance the decisions making.

Furthermore, a significant result of this study that also has not been examined in previous studies suggests that the relative importance of the VST is higher than the relative importance of the F\&C technique in the proposed comprehensive model. This emphasises that the value stream decision making tool better affected decision making than $F \& C$ costing in the lean context. This also means that the VST is the key tool used to provide decision makers with the useful information and increases the effectiveness of decision making in the lean context, and F\&C technique is used in special cases in when product cost is required for some decisions purpose. This finding is also strongly supported by Debusk and Debusk (2012-2014 part IV \&V) who suggested the use of FC technique in the special decision only.

\section{The implication of the proposed model in the Egyptian pharmaceutical industry}

The proposed model allows the value stream managers to make the decisions required to drive profitability and growth within the value stream. The proposed model is valuable to lean companies because it provides decision makers with useful information by more directly linking accounting and production reports to lean concepts. The decision making must be focused on evaluating the impact of the decision on profitability and available capacity of the whole value stream level, not at the 
product level. The information provided by the proposed model enables managers to make highly informed data-driven business decisions and enhances decision making in the Egyptian pharmaceutical industry because it is easy to understand and use, readily available each week, accurate, timely and real information instead of the less accurate information and the complex system of calculating product cost.

This proposed model provides managers in the Egyptian pharmaceutical industry with very useful information in some strategic decisions such as pricing of products and determines which products to sell, using F\&C technique. In addition, studying the differences between customer value and average cost of the product features, provide managers with relevant information for decision making such as cost reduction decisions to close the gap between cost and customer value.

\section{Conclusion}

There has been a lack of attention paid by researchers to studying the integration between management accounting techniques that affect decision making in the lean context. There has also been a lack of care given by researchers to examine the influence of such integration on the effectiveness of decision making. This paper makes a number of distinct contributions to the management accounting literature. The key contribution of this study is the proposition of a value stream decision making tool to provide decision makers with useful information for routine decision making purpose, which has not been addressed in previous literature. The major contribution of this paper is the proposition of a comprehensive model for support decision making in the lean context. This model focuses on using together with the most appropriate management accounting techniques to provide decision makers with the useful information for all decisions making in the lean context. Moreover, this model creates acomprehensive database that can be used in enhancing the effectiveness of decision-making process in the lean context. It highlights the characteristics of cost information created from the integration of the proposed management accounting techniques and how these characteristics are related to the characteristics of useful information, which also has not been addressed in previous literature. Furthermore, the empirical examination of this integration has not been addressed in the existing literature. The 
study was conducted in the Egyptian pharmaceutical industry and provides specific information of value in this specific industry.

The quantitative analysis of the proposed comprehensive model indicated that the integration between value stream tool and $F \& C$ technique are significant in predicting decision making in the lean context. A key result was that the comprehensive model was the best model in predicting a higher level of decision making. Asignificant result was that the relative importance of value stream decision making tool in the comprehensive model is much higher than the $F \& C$ costing.

As with any study, there are limitations. This study was conducted only in a single country and in a single industry that of the Egyptian pharmaceutical industry, such a focus could be viewed as a limitation. The findings of this study are influenced by the particular nature and characteristics of the Egyptian pharmaceutical industry. Therefore, the generalisation of findings beyond the Egyptian pharmaceutical industry should be made with caution. Another limitation is that the use of judgement sampling in the current study may increase the risk of producing bias and inefficient parameter estimates, which should be taken into consideration (Guo and Hussey, 2004). However, judgement sampling is the best choice in the current study for reasons related to the availability of data and to ensure access to qualified respondents in Egyptian pharmaceutical industry.

The current study found that the information provided by the proposed tool which based on the value stream tool and F\&C techniques are related to the decision making in the lean context. However, further examination of the influence of the nonfinancial value stream measures on decision making might be required. The influence of using financial and non-financial value stream measures on decision making as a comprehensive view to enhancing decision-making process is another interesting area for future research. Further works are also needed to analyse and examine the cost and benefits of using the $F \& C$ technique in decision making in the lean context. 


\section{References:}

Anonymous. "The Multiple Linear Regression Analysis in SPSS - Statistics Solutions ". Retrieved 1/7/2016, from www.statisticssolutions.com/the-multiple-linear-regressionanalysis-in-spss/.

Anonymous. "Multiple Regression." Retrieved 1/1/2016, from <http://www.oswego.edu/Documents/psychology/spss/mregress.p df $>$.

Baggaley, B. (2010). "Using strategic preformance measurements to accelerate lean performance." Cost Management 20(1): 36-44.

Baggaley, B. and B. Maskell (2003). "Value stream management for lean companies, part I." Journal of cost management 17(2): 23-27.

Baggaley, B. and B. Maskell (2003). "Value stream management for lean companies, part II." Journal of Cost Management 17(3): 24-30.

Carnes, K. and S. Hedin (2005). "Accounting for lean manufacturing:Another missed opportunity?" Management Accounting Quarterly 7(1): 28-35.

Debusk, G. (2015). "Use lean to add value to the organization." Journal of Corporate Accounting \& Finance 23(3): 29-35.

Debusk, G. and C. Debusk (2012). "The case for lean Accounting:Part I." Cost Management 26(3): 20-24.

Debusk, G. and C. Debusk (2012). "The case for lean Accounting:Part II- Value stream costing." Cost Management 26(4): 22-30.

Debusk, G. and C. Debusk (2014). "The case for lean accounting: Part IV-Features and Characteristics costing." Cost Management January/February: 34-38.

Debusk, G. and C. Debusk (2014). "The case for lean accounting: Part V- The closing argument." Cost Management July/August: 29-33. 
DeLuzio, M. (2006). "Accounting for lean." Manufacturing Engineering 137(6): 83-89.

Dimi, O. (2015). Aspects Regarding the Application of Lean Accounting in Taking the Managerial Decisions. Ovidius University Annals, Economic Science Series. XV(1)

FEI (2015). Achievement. Cairo, Federation of Egyptian industries.

Gordon, G. (2010). "Value stream costing as a management strategy for operational improvement." Cost Management 24(1): 11-17.

Guo, S. and D. Hussey (2004). "Non-probability sampling in social work research: dilemmas, consequences, and strategies " Journal of Social Service Research 30(3): 1-18.

Hair, J., A. Money, et al. (2007). Research Methods for Business., West Sussex: Johan Wiley\& Sons.

Haskin,D (2010). Teaching Special Decisions In A Lean Accounting Environment, American Journal of Business Education -3(6): 91-96.

Hilker, C. (2011). "Effective cost management for lean enterprise." Cost Management 25(4): 17-22.

Howitt, D. and D. Cramer (2008). Introduction to SPSS in Psychology for Version 16 and Earlier, Essex: Pearson Education Limited.

James, W. and J. Daniel (1996). lean thinking: Banish waste and create wealth in your corporation. New York, Simon\&Shuster.

Kennedy, F. and P. Brewer (2005). "Lean Accounting: What's it all about?" Strategic Finance 87(5): 26-34.

Kennedy, F. and J. Huntzinger (2005). "Lean Accounting: measuring and managing the value stream." Cost Management 19(5): 31-38. 
Maskell, B. (2000). "Lean Accounting for lean manufacturers." Manufacturing Engineering 125(6): 46-53.

Maskell, B. (2006). "Solving the standard cost problem." Cost Management 20(1): 27-35.

Maskell, B. and F. Kennedy (2007). "Why do we need lean Accounting and how does it work?" The journal of Corporate Accounting \& finance (March/April): 59-73.

Maskell, B. and F. Kennedy,et al. (2012). "Practical Lean Accounting", Second Edition, CRC press, New York.

Romney, M., P. Steinbert, et al. (2006). Accounting Information Systems. USA, Prentice Hall.

Senge, P. (2007). "Lean Accounting- Best Practices for Sustainable Integration", John Wiley \&Sons, New Jersey.

Tabachnick, B. and Fidell, L. (2001), Using Multivariate Statistics, 4th ed., Allyn and Bacon, Boston,MA.

Van, A. and J. Thomson (2007). "The lowdown on lean Accounting." Strategic Finance 88(8): 26-33.

Velicer, W. and Fava, J. (1998), "Effects of variable and subject sampling on factor pattern recovery", Psychological Methods, Vol. 3 No. 2, pp. 231-251. 


\section{Appendix 1}

Response Bias Test

\begin{tabular}{|c|c|c|c|c|}
\hline Variables & Mann-Whitney U & Wilcoxon W & $\mathbf{Z}$ & $\begin{array}{l}\text { Asymp. } \\
\text { Sig. } \\
\text { (2-tailed) }\end{array}$ \\
\hline V1 & 1577.500 & $\mathbf{3 4 0 7 . 5 0 0}$ & -1.296 & .195 \\
\hline V2 & 1763.000 & 3593.000 & -.210 & .834 \\
\hline V3 & 1580.000 & 3410.000 & -1.217 & .224 \\
\hline V4 & 1678.000 & 3508.000 & -.694 & .488 \\
\hline V5 & 1777.500 & 3607.500 & -.128 & .898 \\
\hline V6 & 1623.500 & 3453.500 & -1.052 & .293 \\
\hline V7 & 1555.500 & 3385.500 & -1.423 & .155 \\
\hline V8 & 1737.000 & 3567.000 & -.348 & .728 \\
\hline V9 & 1723.500 & 3553.500 & -.427 & .669 \\
\hline V10 & 1603.000 & 3433.000 & -1.104 & .269 \\
\hline V11 & 1763.000 & 3593.000 & -.213 & .831 \\
\hline V12 & 1365.000 & 3195.000 & -2.634 & .008 \\
\hline V13 & 1794.500 & 3624.500 & -.030 & .976 \\
\hline V14 & 1681.000 & 3511.000 & -.677 & .498 \\
\hline V15 & 1735.500 & 3565.500 & -.364 & .716 \\
\hline V16 & 1670.500 & 3500.500 & -.729 & .466 \\
\hline V17 & 1712.500 & 3542.500 & -.488 & .626 \\
\hline V18 & 1748.000 & 3578.000 & -.295 & .768 \\
\hline V19 & 1647.500 & 3477.500 & -.866 & .386 \\
\hline V20 & 1441.000 & 3271.000 & -2.083 & .037 \\
\hline V21 & 1783.000 & 3613.000 & -.100 & .920 \\
\hline V22 & 1677.500 & 3507.500 & -.699 & .485 \\
\hline V23 & 1557.000 & 3387.000 & -1.420 & .156 \\
\hline V24 & 1683.000 & 3513.000 & -.708 & .479 \\
\hline V25 & 1611.000 & 3441.000 & -1.064 & .287 \\
\hline V26 & 1575.500 & 3405.500 & -1.276 & .202 \\
\hline V27 & 1515.000 & 3345.000 & -1.584 & .113 \\
\hline V28 & 1591.500 & 3421.500 & -1.158 & .247 \\
\hline V29 & 1770.000 & 3600.000 & -.166 & .868 \\
\hline V30 & 1719.500 & 3549.500 & -.445 & .657 \\
\hline V31 & 1760.000 & 3590.000 & -.222 & .824 \\
\hline V32 & 1703.500 & $\mathbf{3 5 3 3 . 5 0 0}$ & -.539 & .590 \\
\hline V33 & 1734.000 & 3564.000 & -.378 & .706 \\
\hline V34 & 1700.500 & 3530.500 & -.549 & .583 \\
\hline
\end{tabular}

